\title{
Analisa Pengaruh Berat Pengemudi terhadap Deformasi pada Rangka Utama Sepeda Penyapu Sampah
}

\author{
Muhammad Hasan Albana*, Budi Sukmana* \\ * Batam Polytechnics \\ Mechanical Engineering study Program \\ Jln. Ahmad Yani, Batam Centre, Batam 29461, Indonesia \\ E-mail: hasan@polibatam.ac.id
}

\begin{abstract}
Abstrak
Sepeda penyapu sampah adalah alat yang dirancang dan dibuat agar membantu kerja seseorang menjadi lebih efisien dibandingkan dengan menyapu sampah secara manual menggunakan tangan. Alat ini memiliki rangka utama yang menjadi tempat sistem-sistem serta komponen-komponen tersebut diletakkan. Ketika sepeda dikendarai, nilai berat manusia khususnya pada sadel sepeda menghasilkan tekanan, tekanan tersebut secara langsung berpengaruh pada rangka utama sehingga rangka mengalami deformasi. Oleh karena itu untuk mengetahui berat maksimum pengemudi yang dapat diterima oleh rangka, sehingga rangka sepeda penyapu sampah tidak mengalami deformasi dan dapat dioperasikan secara optimal maka dibutuhkan pengujian. Penelitian ini dilakukan secara simulasi menggunakan software Solidworks 2013, menggunakan fitur simulasi statis sehingga nilai tegangan yang terjadi dapat diketahui. Material yang digunakan pada rangka adalah baja ST. 37 yang termasuk dalam golongan baja karbon rendah. Adapun berat pengemudi yang diujikan seberat $60 \mathrm{~kg}$ hingga $120 \mathrm{~kg}$. Setelah dilakukan pengujian, hasil yang didapatkan pada berat $60 \mathrm{~kg}$ sampai $120 \mathrm{~kg}$ tegangan maksimal 37,839 Mpa serta defleksi sebesar 0,202 mm yang berarti defleksi yang terjadi sangat kecil, nilai faktor keamanan paling minimum 3,58 yang termasuk dalam kategori aman secara keseluruhan desain. Untuk berat maksimal yang dapat diterima oleh sepeda penyapu sampah yaitu $280 \mathrm{Kg}$, dengan tegangan maksimal yang terjadi 105,669 MPa dengan perubahan bentuk/defleksi sebesar 0,463 mm, serta nilai faktor keamanan paling minimum sebesar 1,5 yang berarti batas dari nilai aman struktur desain.
\end{abstract}

Kata kunci: Deformasi, Rangka, Solidworks 2013

\begin{abstract}
Bicycles garbage sweeper is a tool designed and made to help person becomes more efficient than manually sweep garbage by hand. This tool has a main frame into place systems and components are placed. When the bike ridden, the pressure directly affects the main frame and maked the frame deformation. To know the maximum weight of the driver which can be received by the framework, so that the garbage sweeper bike frame does not deform and can be operated optimally, need a research. This research was done by simulation using Solidworks Software 2013, using a static simulation features so that the value of the stress that occurred can be known. The material used in the frame is ST. 37 Steel which included in the class of low carbon steel. The driver who tested the burden weighing $60 \mathrm{~kg}-120$ $\mathrm{kg}$ (maximum) gradually so obtained is determined whether the frame is experiencing excessive deformation. After testing the results obtained on the load of $60 \mathrm{~kg}-120 \mathrm{~kg}$ maximum stress of $37,839 \mathrm{MPa}$ and a deflection of 0,202 $\mathrm{mm}$, which means a very small deflection occurs, the value of the minimum safety factor of 3,58 is included in the safe category overall design. For maximum load that can be accepted by bicycles garbage sweeper is $280 \mathrm{~kg}$, with a maximum stress that occurs 105,669 MPa with deformation / deflection of 0,463 $\mathrm{mm}$, and the minimum value of the safety factor of 1,5 , which means the limit of the value of design safer structures.
\end{abstract}

Keywords: Frame, Deformation, Solidworks 2013 


\section{Pendahuluan}

Sepeda penyapu sampah adalah alat yang dirancang dan dibuat agar membantu kerja seseorang menjadi lebih efisien dibandingkan dengan menyapu sampah secara manual menggunakan tangan, alat ini masih tergolong baru karena sistem yang diaplikasikan berbeda dengan alat penyapu sampah yang sudah ada sebelumnya. Menggunakan sistem putaran dari ban belakang sepeda yang menggerakkan ban depan sepeda yang terhubung dengan poros sapu sehingga sapu berputar dan sampah dibawa melalui konveyor dialirkan sampai pada bak penampung sampah. Alat ini memiliki rangka utama yang menjadi tempat sistem-sistem serta komponen tersebut diletakkan, rangka tersebut dihubungkan oleh sepeda yang pada bagian garpu sepeda terdapat joint yang dihubungkan dengan joint rangka menggunakan baut M8.

Ketika sepeda dikendarai, nilai berat manusia khususnya pada sadel sepeda menghasilkan tekanan, tekanan tersebut secara langsung berpengaruh pada rangka utama sehingga rangka utama mengalami deformasi. Dengan analisa yang belum maksimal pada pembuatannya, penelitian ini ditujukan untuk mengetahui beban statis menggunakan software Solidworks 2013. Selain untuk merancang suatu model desain, software ini juga dapat digunakan untuk menjalankan beberapa jenis simulasi, salah satunya simulasi statis, analisis gerakan (motion) dan temperatur [1]. Secara umum ter- dapat dua kategori mengenai beban, yaitu beban statis, beban yang memiliki perubahan intensitas beban terha- dap waktu yang berjalan lambat atau konstan dan be- ban dinamis, beban dengan variasi perubahan intensi- tas beban terhadap waktu yang cepat [2].

Variabel yang dihasilkan pada penelitian ini diantaranya nilai tegangan von Mises, yaitu tegangan yang digunakan untuk memprediksi tingkat keluluhan material terhadap kondisi pembebanan dari hasil pengujian tarik simple uniaksial [3]. Nilai deformasi, yang artinya semua struktur bila mendapat berat luar akan berubah sedikit dari bentuk awalnya, baik berubah bentuk maupun ukurannya. Bertambahnya ukuran dari sebuah struktur disebut perpanjangan atau elongasi, sedangkan sebaliknya disebut pemendekan atau konstraksi. Pada struktur yang mendapatkan deformasi yang normal dari masing-masing elemennya berada pada sifat elastis, maka kondisi tersebut disebut kondisi kekakuan (condition of rigidity) [4].

Agar tercapai desain aman elemen struktur, ditentukan suatu faktor keamanan, yaitu perbandingan tegangan patah (failure strength) terhadap tegangan aktual, karena faktor keamanan dan tegangan aktual tidaklah berhubungan dan tergantung pada banyak faktor, nilainya akan berkisar antara 1,5-20, serta nilai faktor keamanan untuk logam ulet (ductile metals) seperti baja yang dikenakan berat statis, nilai faktor keamanan adalah 1,5 [5], sehingga didapatkan berapa berat maksimum pengendara yang mampu diterima oleh rangka utama secara desain keseluruhan.

\section{Metode Penelitian}

Pada pembuatan dan desain rangka utama dan sepeda penyapu sampah digunakan material Baja ST.37. Joint garpu sepeda dan joint rangka utama dihubungkan oleh 2 buah baut/bolt kepala L ukuran M8, masing-masing pada satu joint. Pada penelitian ini, dilakukan percobaan berat pengendara dari $60 \mathrm{~kg}$ (minimal) hingga 120 $\mathrm{kg}$ (maksimal) secara bertahap dengan penambahan nilai $10 \mathrm{Kg}$ pada setiap pengujiannya, dari data ini, dilakukan perhitungan mengenai nilai gaya, dari hasil data tersebut dapat dilakukan uji simulasi statis menggunakan software Solidworks 2013 dan diketahui bagian rangka utama yang terkena tegangan tertinggi dan deformasi karena berat pengendara, untuk berat rangka utama yaitu $6,31 \mathrm{~kg}$, data tersebut diketahui menggunakan fitur mass properties pada software Solidworks 2013 [6].

Jika pada berat $120 \mathrm{~kg}$ nilai faktor keamanan belum mencapai angka 1,5, pengujian dilanjutkan dengan penambahan nilai $10 \mathrm{~kg}$ pada setiap pengujian, sampai nilai faktor keamanan mencapai 1,5. Untuk mengetahui berat maksimum pengendara yang dapat diterima oleh rangka utama.

Tabel 1. Klasifikasi Baja Karbon [7]

\begin{tabular}{|c|c|c|c|c|c|c|c|}
\hline Jenis & Kelas & $\begin{array}{c}\begin{array}{c}\text { Kadar karbon } \\
(\%)\end{array} \\
\text { (a) }\end{array}$ & 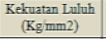 & $\begin{array}{c}\text { Kekuatan Tanik } \\
\text { (Kggmm2) }\end{array}$ & Perpajjangan & $\begin{array}{c}\text { Kekerasan } \\
\text { Brinell }\end{array}$ & Penggunan \\
\hline \multirow[t]{4}{*}{$\begin{array}{l}\text { Baja karbon } \\
\text { Rendah }\end{array}$} & $\begin{array}{l}\text { Bajallunak } \\
\text { khousus }\end{array}$ & 0,08 & $18-28$ & $32-36$ & $40-30$ & 95-100 & Pelat tipis \\
\hline & $\begin{array}{l}\text { Baja sangat } \\
\text { lunak }\end{array}$ & $0,08-0,12$ & $20-29$ & $36-42$ & $40-30$ & 80-120 & Batang kawat \\
\hline & Bajal lualk & $0,12-0,20$ & $22-30$ & $38-48$ & $36-24$ & $\begin{array}{l}100-130 \\
\end{array}$ & \multirow{2}{*}{ 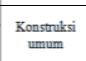 } \\
\hline & $\begin{array}{l}\text { Baja setetengs } \\
\text { lunak }\end{array}$ & $0,20-0,30$ & $24 \cdot 36$ & $44-45$ & $32-22$ & $117-145$ & \\
\hline $\begin{array}{l}\text { Baja karbon } \\
\text { sedang }\end{array}$ & $\begin{array}{l}\begin{array}{l}\text { Baja setengahh } \\
\text { keras }\end{array} \\
\text { tor }\end{array}$ & 0.300 .040 & 30.40 & 50.60 & $30-17$ & $140-170$ & $\begin{array}{c}\begin{array}{c}\text { Alat-alat } \\
\text { mesin }\end{array} \\
\text {. }\end{array}$ \\
\hline \multirow{2}{*}{$\begin{array}{l}\text { Baja karbon } \\
\text { tingsi }\end{array}$} & Baja keras & 0:04-0,50 & 34.46 & $58-70$ & $26-14$ & $160-200$ & Perkikasas \\
\hline & $\begin{array}{l}\begin{array}{l}\text { Baja sangat } \\
\text { keras }\end{array} \\
\end{array}$ & $0,50-0,80$ & $36-47$ & $65-100$ & $20-11$ & $180-235$ & \begin{tabular}{|l} 
Rel, pegas dan \\
kamat piano
\end{tabular} \\
\hline
\end{tabular}

Tabel 2. Karateristik Baja ST. 37 pada Software Solidworks 2013

\begin{tabular}{|l|l|l|}
\hline Property & Value & Units \\
\hline Elastic Modulus in X & 205000 & $\mathrm{~N} / \mathrm{mm} 2$ \\
Poisson's Ration in XY & 0,29 & N/A \\
Shear Modulus in XY & 80000 & $\mathrm{~N} / \mathrm{mm} 2$ \\
Mass Density & 7870 & $\mathrm{~kg} / \mathrm{m} 3$ \\
Tensile Strength in X & 385 & $\mathrm{~N} / \mathrm{mm} 2$ \\
Yield Strength & 325 & $\mathrm{~N} / \mathrm{mm} 2$ \\
Thermal Expansion Coefficient in X & $1.20 \mathrm{E}-05$ & $/ \mathrm{K}$ \\
Thermal Conductivity in X & 52 & W/(m-K) \\
Specific Heat & 486 & $(\mathrm{~kg}-\mathrm{K})$ \\
\hline
\end{tabular}

Langkah pertama, rancang ulang bentuk desain rangka utama, menentukan jenis material, pada alat yang telah jadi. Kemudian diberikan uji dengan memberikan nilai massa (Kg) manusia sebesar 60 kg-120 kg ditambah 10 $\mathrm{Kg}$ secara bertahap. Konversi massa (kg) menjadi gaya 
(N) dengan memasukkan nilai gravitasi dan dari data tersebut dimasukkan dalam pengujian statis sehingga akan diketahui bagian yang terkena tegangan (stress), panjang defleksi (displacement), sedangkan untuk mengetahui besaran nilai factor of safety/faktor keamanan dengan menerapkan perbandingan antara besar yield strength dengan besar design stress dari tiap material [8], yang akan secara otomatis dikalkulasikan oleh software Solidworks 2013.

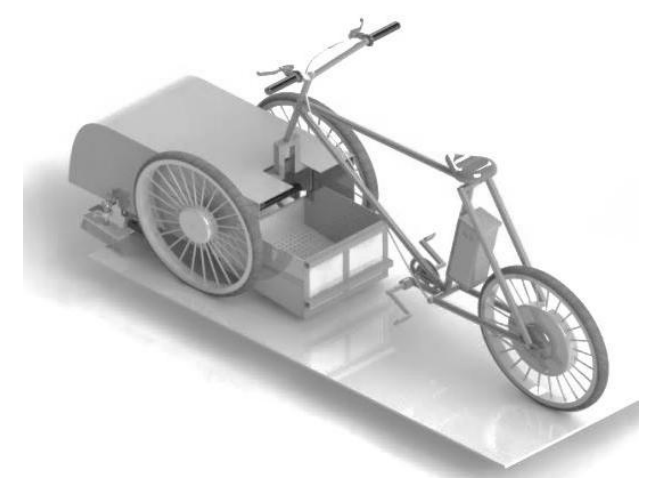

Gambar 1. Desain Sepeda Penyapu Sampah

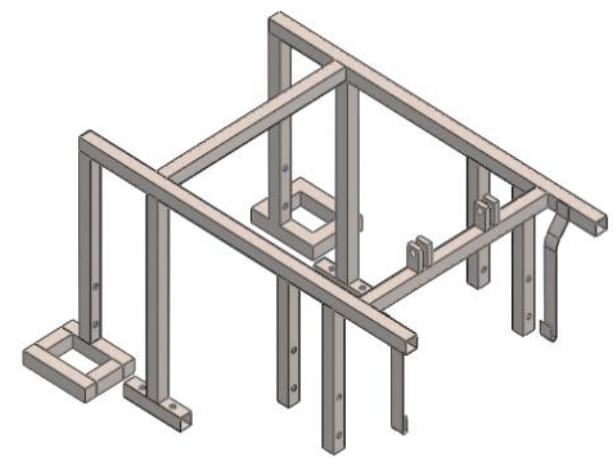

Gambar 2. Rangka Utama

Adapun prosedur uji simulasi statis dijabarkan seperti berikut :

1. Open assembly sepeda penyapu sampah.

2. Masuk pada tab simulasi, study advisor.

3. Pemilihan uji static.

4. Pemilihan jenis material setiap komponen.

5. Penentuan fixed geometry yaitu tumpuan sepeda penyapu sampah dalam pengujian ini 5 titik poros 3 titik pada ban sepeda, dan 2 dudukan roda troli sebagai titik tumpu,.

6. Pemilihan external load advisor untuk nilai force atau gaya yang diberikan.

7. Plane dasar untuk peletakan gaya gravitasi.

\section{Uji simulasi dapat dilakukan.}

Proses pemasukan (input) data pada uji statis simulasi Solidworks 2013, yaitu data: force, gravity plane, fixed geometry dan material. Force adalah gaya yang diberikan, gravity plane adalah arah plane yang dipilih dengan mengacu pada letak desain secara isometrik, sehingga benda seperti dalam pengaruh gravitasi bumi, Fixed geometry adalah pemilihan titik tumpu pada sepeda dan rangka utama dan material, pemilihan terhadap jenis material yang digunakan dalam desain.

Pada pengujian ini, desain pada software Solidworks 2013 disesuaikan dengan bentuk dan dimensional yang sama dengan alat yang sebenarnya. Untuk mengetahui berat rangka utama dilakukan evaluasi dengan fitur mass properties pada software Solidworks 2013.

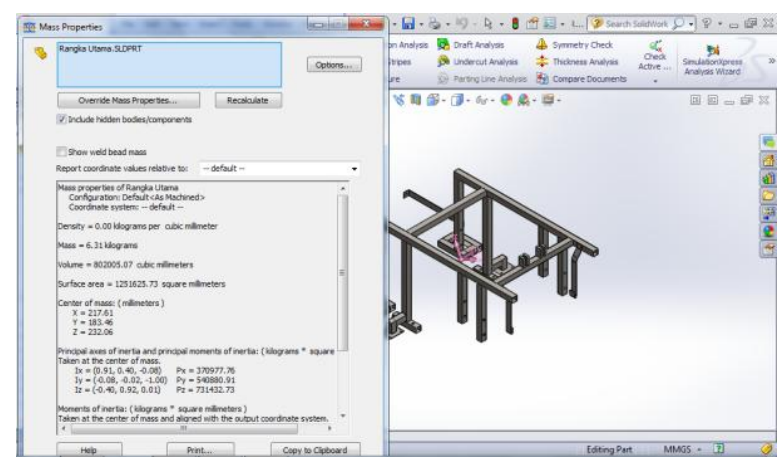

Gambar 3. Berat Rangka Utama Menggunakan Mass Properties pada Solidworks 2013

Nilai berat pengendara yang diujikan secara variabel mengacu pada berat ideal manusia dari $60 \mathrm{Kg}-120 \mathrm{Kg}$, secara bertahap dengan 7 kali pengujian dimana jarak setiap pengujian ditambahkan nilai berat pengendara sebesar $10 \mathrm{Kg}$.

Data pengujian yang didapatkan meliputi tegangan (stress), perubahan bentuk material/deformasi (displacement), faktor keamanan (factor of safety) dalam bentuk visual yang menunjukkan bagian tersebut, karena hasil pengujian antara nilai $60 \mathrm{~kg}-120 \mathrm{~kg}$ tidak terlalu signifikan perbedaannya, maka hasil yang ditampilkan secara rinci hanya pada nilai $60 \mathrm{~kg}$ dan $120 \mathrm{~kg}$, sedangkan pada nilai lainnya hasil pengujian ditampilkan dalam tabel.

Pada simulasi statis Solidworks 2013, komponen yang dirakit yaitu rangka utama material baja ST.37, rangka sepeda material baja ST.37, poros ban depan, dan belakang material baja ST.37, pin penghubung rangka utama dengan rangka sepeda material baja ST.37. Berat pengendara diberikan pada sadel sepeda dengan 5 titik tumpu (fixed geometry) dalam hal ini poros ban sepeda depan sisi kanan-kiri, belakang dan landasan roda troli sisi kanan-kiri. Dari massa satuan (kg) dikon- versikan menjadi gaya/force (Newton) dengan menga- likan massa tersebut dengan percepatan gravitasi bumi yaitu $9,8 \mathrm{~kg} / \mathrm{m}^{2}$. 


\section{Hasil dan Pembahasan}

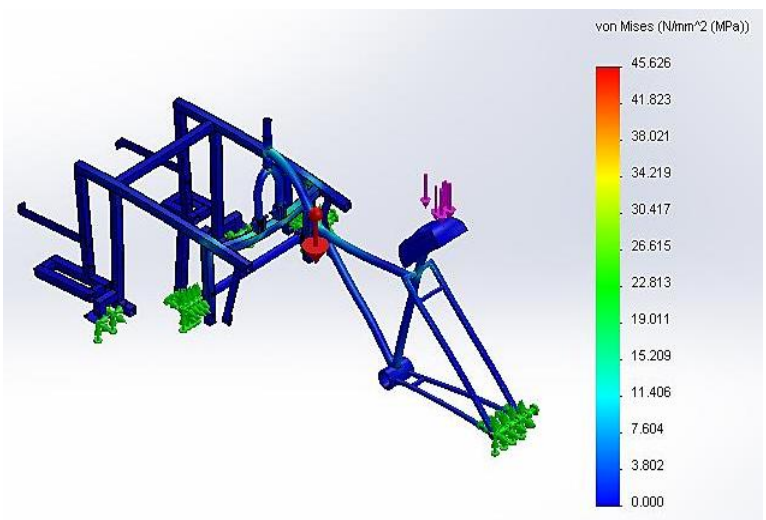

Gambar 4. Nilai tegangan untuk massa $60 \mathrm{~kg}$

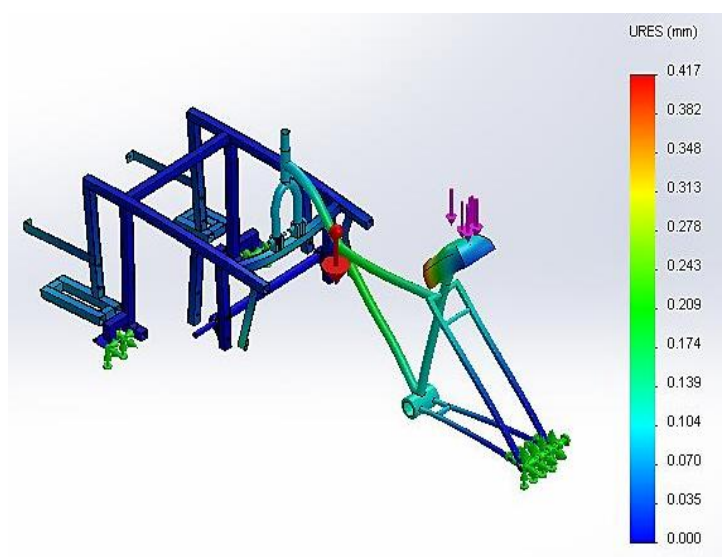

Gambar 5. Nilai displacement untuk massa $60 \mathrm{~kg}$

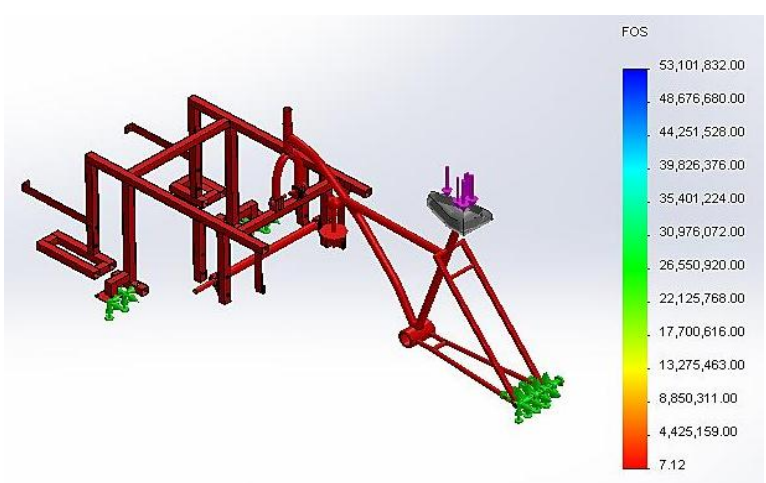

Gambar 6. Nilai Faktor Keamanan untuk massa 60 kg

Gambar 4 memperlihatkan hasil semulasi tegangan untuk massa $60 \mathrm{~kg}$ dimana nilai tegangan von Mises tertinggi yang diperoleh adalah 19,011 Mpa dan berada dikisaran warna hijau (nilai tegangan sedang) yang dialami oleh rangka utama, tepatnya pada batang joint rangka utama dengan joint rangka sepeda. Perubahan bentuk (displacement) tertinggi untuk massa $60 \mathrm{~kg}$ ditunjukkan pada Gambar 5 dimana nilai displacement yang terjadi adalah sebesar 0,104 mm. Untuk faktor keamanan diperlihatkan pada Gambar 6 dimana faktor keamanan yang diperoleh adalah 7,12 yang berarti secara keseluruhan desain ini aman bila diberikan massa sebesar $60 \mathrm{Kg}$.

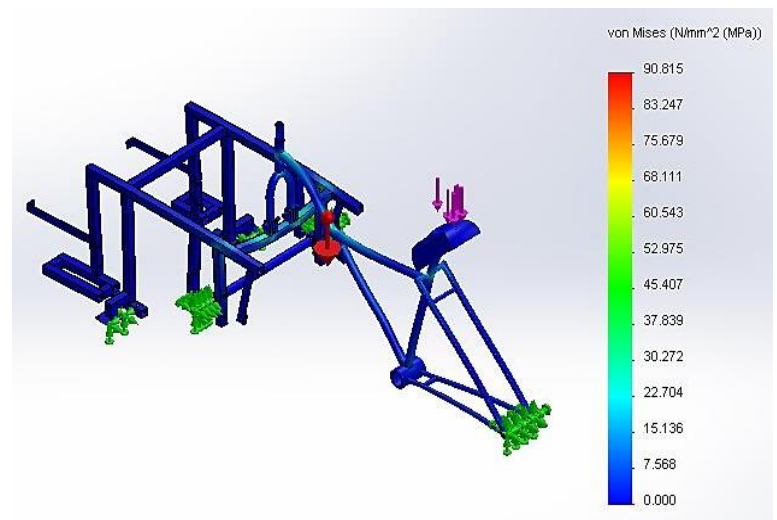

Gambar 7. Nilai tegangan untuk massa $120 \mathrm{~kg}$

Gambar 7 memperlihatkan tegangan von misses yang terjadi ketika sepeda penyapu sampah diberi massa sebesar $120 \mathrm{~kg}$. Tegangan von misses tertinggi yang terjadi adalah 37,839 $\mathrm{MPa}$ berada dikisaran warna hijau (nilai tegangan sedang) yang dialami oleh rangka utama, tepatnya pada batang letak joint rangka utama dengan joint rangka sepeda.

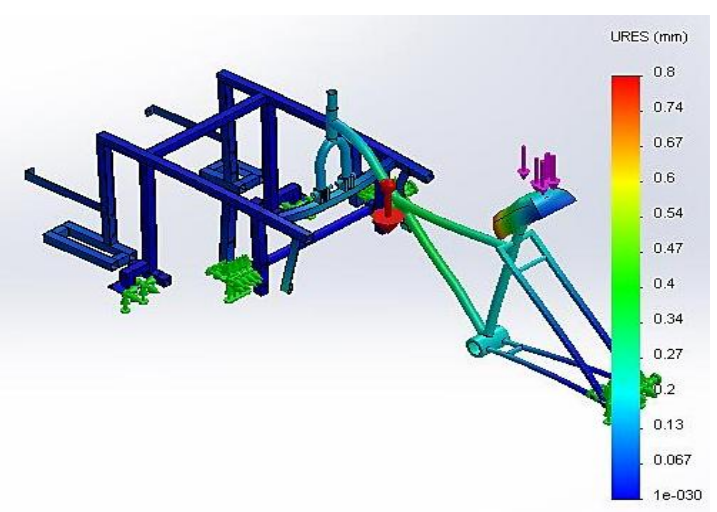

Gambar 8. Nilai displacement untuk massa $120 \mathrm{~kg}$

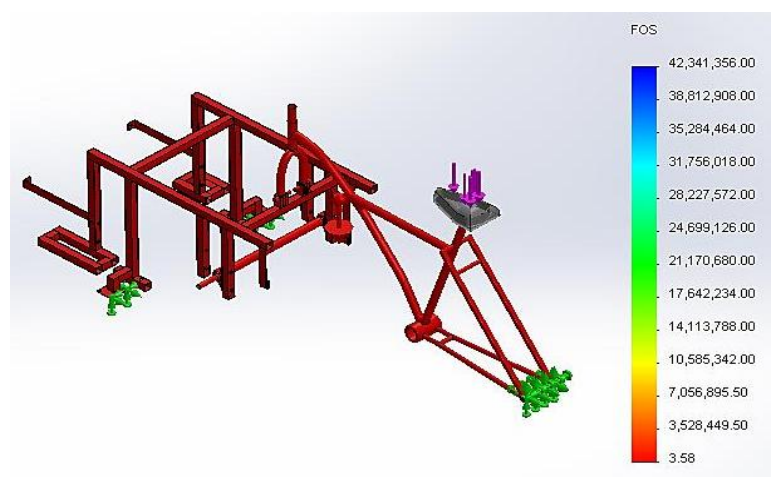

Gambar 9. Nilai Faktor Keamanan untuk massa 120 $\mathrm{kg}$ 
Gambar 8 memperlihatkan displacement yang terjadi ketika diberi massa $120 \mathrm{~kg}$. Displacement tertinggi yang terjadi pada rangka utama adalah sebesar 0,202 $\mathrm{mm}$. Adapun faktor keamanan ketika diberi massa adalah 3,58 sebagaimana diperlihatkan pada Gambar 9 . Hal ini berarti secara keseluruhan desain ini aman bila diberikan berat sebesar $120 \mathrm{Kg}$.

Tabel 3. Perbandingan Hasil Tegangan (Stress)

\begin{tabular}{|c|c|c|}
\hline $\begin{array}{c}\text { Massa } \\
(\mathbf{k g})\end{array}$ & $\begin{array}{c}\text { Gaya } \\
(\mathbf{N})\end{array}$ & $\begin{array}{c}\text { Tegangan } \\
(\mathbf{M P a})\end{array}$ \\
\hline 120 & 1176 & 37,839 \\
\hline 110 & 1078 & 34,737 \\
\hline 100 & 980 & 31,577 \\
\hline 90 & 882 & 28,423 \\
\hline 80 & 748 & 25,288 \\
\hline 70 & 686 & 22,149 \\
\hline 60 & 588 & 19,011 \\
\hline
\end{tabular}

Tabel 4. Perbandingan Hasil Displacement

\begin{tabular}{|c|c|c|}
\hline $\begin{array}{c}\text { Massa } \\
(\mathbf{k g})\end{array}$ & $\begin{array}{c}\text { Gaya } \\
(\mathbf{N})\end{array}$ & Displacement $(\mathbf{m m})$ \\
\hline 120 & 1176 & 0,202 \\
\hline 110 & 1078 & 0,186 \\
\hline 100 & 980 & 0,170 \\
\hline 90 & 882 & 0,153 \\
\hline 80 & 748 & 0,137 \\
\hline 70 & 686 & 0,121 \\
\hline 60 & 588 & 0,104 \\
\hline
\end{tabular}

Tabel 3 dan Tabel 4 memperlihatkan nilai tegangan dan displacement yang dialami oleh rangka utama sepeda motor ketika diberi beban $60 \mathrm{~kg}, 70 \mathrm{~kg}, 80 \mathrm{~kg}, 90 \mathrm{~kg}$, $100 \mathrm{~kg}, 110 \mathrm{~kg}$ dan $120 \mathrm{~kg}$. Dari Tabel tersebut bisa disimpulkan bahwa semakin berat pengendara sepeda penyapu sampah maka semakin besar nilai tegangan yang dialami dan semakin besar displacement yang terjadi.

Karena berat yang diujikan belum menunjukkan tegangan maksimal dan faktor keamanan paling minimum yang dapat diterima oleh rangka utama juga belum diketahui maka dilakukan pengujian kembali supaya diketahui nilai-nilai tersebut. Setelah dilakukan pengujian dari $120 \mathrm{~kg}$ secara bertahap dengan penambahan nilai berat $10 \mathrm{~kg}$ maka ditemukan pada massa $280 \mathrm{~kg}$ menunjukkan nilai faktor keamanan yang paling kecil.

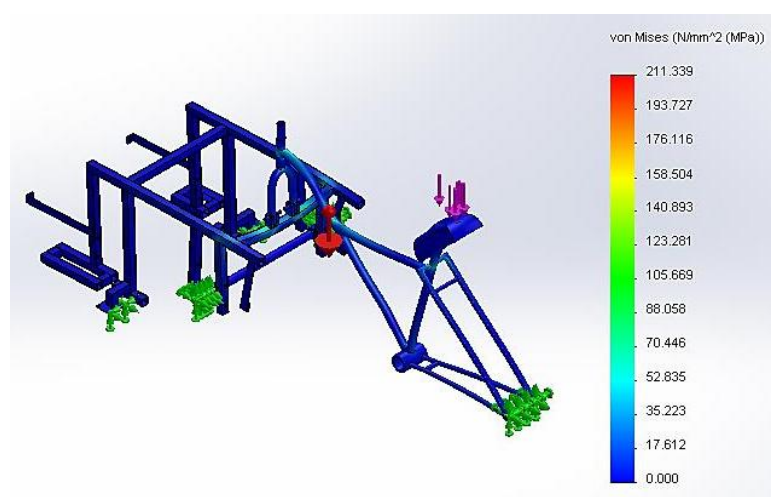

Gambar 10. Nilai tegangan untuk massa $280 \mathrm{~kg}$

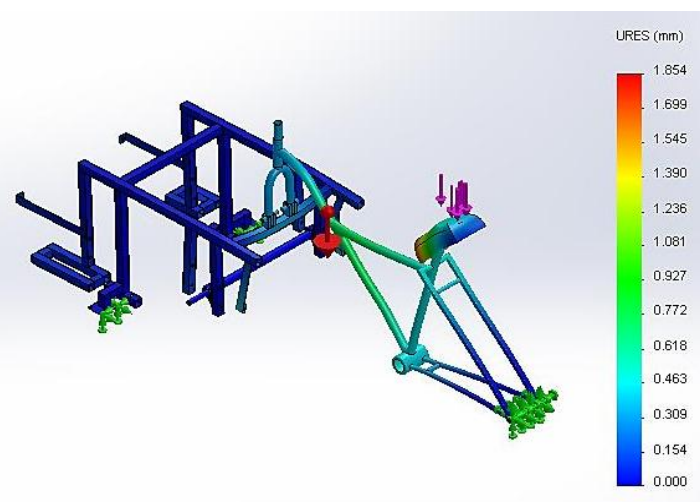

Gambar 11. Nilai displacement untuk massa $280 \mathrm{~kg}$

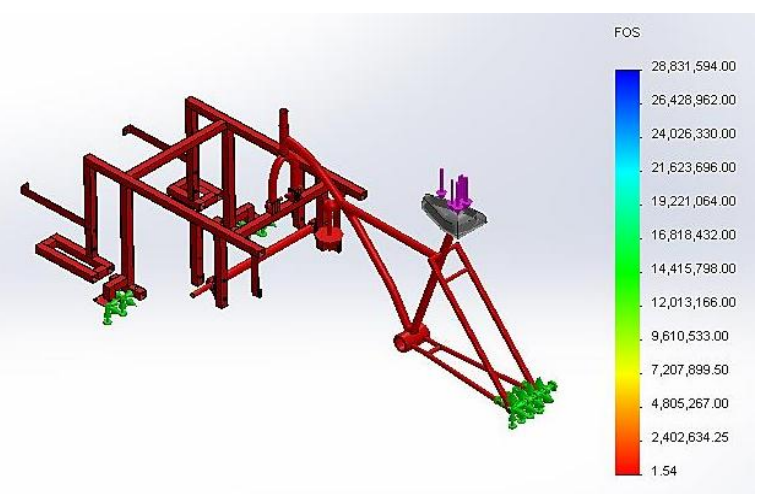

Gambar 11. Nilai Faktor Keamanan untuk massa 280 $\mathrm{kg}$

Pada pemberian massa sebesar $280 \mathrm{Kg}$ ditunjukkan hasil tegangan von Mises maksimal yaitu 105,669 MPa dengan nilai displacement sebesar $0,463 \mathrm{~mm}$, nilai tegangan belum mencapai dengan nilai yield strength material, namun pada hasil faktor keamanan secara struktural telah mencapai nilai 1,5 yang artinya tepat pada batas nilai faktor keamanan. Hasil simulasi untuk untuk massa $280 \mathrm{~kg}$ diperlihatkan pada Gambar 10, Gambar 11, dan Gambar 12. 


\section{Kesimpulan}

Berat pengendara sepeda penyapu sampah sebesar $1176 \mathrm{~N}$ atau dengan massa $120 \mathrm{~kg}$ hanya akan menghasilkan tegangan (stress) sebesar 37,839 Mpa pada rangka utama dan defleksi yang terjadi sebesar 0,202 mm. Rangka utama yang terhubung pada sepeda ketika diberikan berat $120 \mathrm{~kg}$ tidak mengalami defleksi yang berlebihan atau kurang dari $1 \mathrm{~mm}$. Nilai faktor keamanan pada berat $120 \mathrm{~kg}$ yaitu 3,58 lebih dari 1,5 yang berarti secara desain struktur sudah aman untuk digunakan. Sedangkan ketika diberi beban sebesar 2744 N atau dengan massa $280 \mathrm{~kg}$, nilai tegangan yang terjadi pada rangka utama adalah 105,669 $\mathrm{MPa}$, defleksi 0,463 mm dan nilai faktor keamanan 1,54 yang artinya telah mencapai batas aman sesuai variabel faktor keamanan yang ditentukan.

\section{Daftar Pustaka}

[1] Glodova, Iveta, et al, Usage of finite element method for motion and thermal analysis of a specific object in SolidWorks environment, Procedia Engineering, Vol. 96, hal. 131-135, 2014.

[2] Aribowo, Damar dan Eko, Wiratmoko, Perencanaan Gedung Hotel Beringin di Salatiga, Universitas Diponegoro, 2007.

[3] Atmojo, Komarudin Tri dan Sugiyanto, Prediksi Tegangan Von Mises Femoral Stem Pada Sambungan Tulang Pinggul Buatan Menggunakan Metode Elemen Hingga, Universitas Diponegoro, 2012.

[4] Efendi, Agus, Pengaruh Berat dan Tekanan Udara Pada Distribusi Tegangan Velg Jenis Lenso, Universitas Gunadarma, 2009.

[5] Ach. Muhib Zainuri, ST, MT, Kekuatan Bahan, Andi Yogyakarta, Yogyakarta, 2008.

[6] Chang, Kuang-Hua, Design Theory and Methods using CAD/CAE, Elsevier, London, 2015.

[7] Dwima, Anefin dan Kasatriawan, Proses Pembuatan Rangka Pada Mesin Perajang Sampah Organik Sebagai Bahan Dasar Pupuk Kompos, Universitas Negeri Yogyakarta, 2012.

[8] Yulianto, Nano dan Winarsono, Rochmad, Analisa Tegangan Pada Rangka Prototype Kendaraan Buge Menggunakan Elemen Hingga, Universitas Muria Kudus, Kudus, 2013. 